\title{
Agropastoralists' Climate Change Adaptation Strategy Modeling: Software and Coding Method Accuracies for Best- Worst Scaling Data
}

\author{
Zakou Amadou
}

\section{Contents}

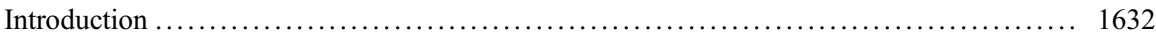

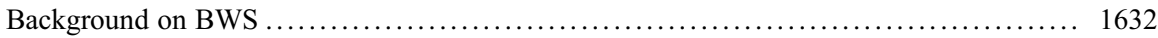

Climate Change Policy Identification and Survey Design ........................ 1633

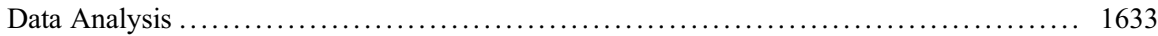

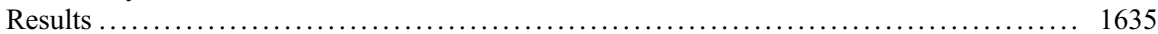

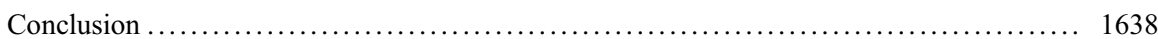

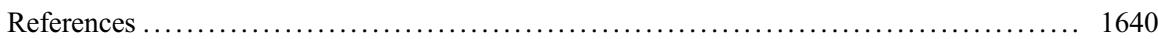

\begin{abstract}
Investigating software and coding method accuracies are still a challenge when dealing with best-worst scaling data. Comparing various climate change policy estimates and their relative importance across different statistical packages has received little attention. In this chapter, we use best-worst scaling approach to determine agropastoralist preferences for 13 climate change adaptation policies across two popular statistical packages (R and SAS). While data were collected from 271 agropastoralists, mixed logit was used to analyze data. Results reveal that mean and standard deviation estimates for 13 climate change adaptation policies from $\mathrm{R}$ are higher and statistically significant than SAS estimates. Based on $\mathrm{R}$ estimates, prolific animal selection, vaccination, settlement, strategic
\end{abstract}

\footnotetext{
This chapter was previously published non-open access with exclusive rights reserved by the Publisher. It has been changed retrospectively to open access under a CC BY 4.0 license and the copyright holder is "The Author(s)". For further details, please see the license information at the end of the chapter.
}

Z. Amadou ( $\square)$

Faculty of Agricultural Sciences, Department of Rural Economics and Sociology, Tahoua University, Tahoua, Niger

e-mail: zakouamadou77@gmail.com 
mobility, and strategic destocking are the most popular climate change adaptation policies, and more than two-third of respondents are in favor of these policies.

\section{Keywords}

Climate change adaptation policies · Best-worst scaling $\cdot$ Agropastoralists · Mixed logit models

\section{Introduction}

A myriad of climate change adaptation policies have been proposed to improve farmers and herdsmen's resilience building capacity, diversify their income and food, and increase their welfare in a changing climate. Several computation methods have been used to analyze discrete choice and best-worst datasets. While conditional logit, multinomial logit have been widely used in the academic literature, the usage of mixed logit (ML) models has been exploded because it is capable to relax (IIA) and can approximate any random utility model (McFadden and Train 2000).

A recent research has studied mixed logit models: accuracy and software choice by comparing ML across three popular packages, namely, SAS, NLOGIT-LIMDEP, and a user-written add-in module for STATA. Results indicate that the data generating process used was not well suited to evaluate the accuracy of software packages and further research is needed to determine which software is the most accurate (Chang and Lusk 2011).

Another challenge is to determine the climate change adaptation policy, and there are few studies geared at computing welfare effects of individual climate change policy. In addition, determining the relative importance of several climate change policy options can be challenging though they may have the same objective towards resilience building. For instance, prolific animal selection and changing herd composition both aim at reducing herd size and thereby enhancing agropastoralists' resilience build capacity. A third challenge facing researcher is to write an algorithm capable of solving real-life problem.

This chapter contributes to fill a knowledge gap by eliciting agropastoralists preference for alternative climate change policies and also enriching literature related to climate change and choice modeling. While data collected from choice experiment and best-worst have been well-documented, coding methods and algorithm development vary considerably from one statistical package to another.

\section{Background on BWS}

Climate change is increasingly becoming recognized as a global threat and concerted effort such as new climate change adaptation strategies should be undertaken both at local, national, and regional and global levels. 
While various government climate change adaptation policies have been proposed to reinforce vulnerable farmers' resilience capacity, little is relatively known about farmers indigenous knowledge related to climate change adaptation strategies. However, not all climate change policies have had expected results on farmers' welfare, and previous studies have indicated that combined government and farmers adaptation strategies are more welfare enhancing (Tabbo et al. 2016).

\section{Climate Change Policy Identification and Survey Design}

Based on previous research and interview with agropastoralists, 13 climate change adaptation policies have been identified and included in this study. To determine the relative importance that agropastoralists place on these policies, a BWS experiment was designed (Marley and Louvriere 2005). A balanced incomplete block design (BIBD) developed by Louviere et al. (2015) has been used to determine allocation of the 13 policies for each BW question. The resulted design contains 13 BWS questions, each having four policy options. The BIBD is the most widely used design in the BWS literature because it is not only a balanced design but also an orthogonal design (Flynn and Marley 2014). Furthermore, the policies were selected to reflect the main issues and challenges recently discussed in climate change adaptation choice as compared to the food choice literature documented by Lusk and McCluskey (2018).

For each BWS question, respondent was asked to select his best and his worst climate change adaptation policies. Figure 1 listed below reports an example of the best-worst questions used in the study.

The coding method used for $\mathrm{R}$ is based on position for each pair of best-worst question. The value for the position can be ranged from 1 to 4 . For SAS, best options will be assigned 1, worst options (-1), and 0 for non-chosen options. This shows that a scale difference may exist between the two coding methods (Table 1).

\section{Data Analysis}

The BWS approach assumes that respondents simultaneously make repeated choices by choosing the best and worst items in a given set and thereby maximizing the difference (Flynn and Marley 2014). By denoting J as number of items in each BWS

\begin{tabular}{|c|l|c|}
\hline Best & Endogenous Strategies & Worst \\
\hline$\square$ & Strategic mobility & $\square$ \\
\hline$\square$ & Transhumance & $\square$ \\
\hline$\square$ & Settlement & $\square$ \\
\hline$\square$ & Income generating income & $\square$ \\
\hline
\end{tabular}

Fig. 1 Please select your best and worst endogenous strategies 
Table 1 Climate change adaptation policy and description

\begin{tabular}{l|l}
\hline Climate change policy & Description \\
\hline Mutual assistance & Helping agropastoralist to rebuild his herd by donating a gift \\
\hline Settlement & Combining farming and animal rearing \\
\hline Strategic mobility & Mobility orientated towards researching forage and water \\
\hline Strategic destocking & $\begin{array}{l}\text { Reducing herd size to accommodate shortage of forage and } \\
\text { drought }\end{array}$ \\
\hline Prolific animal selection & $\begin{array}{l}\text { Keeping animals capable of yielding higher meat and milk } \\
\text { products }\end{array}$ \\
\hline Sheep and cattle fattening & $\begin{array}{l}\text { Increasing sheep and cattle weight by feeding on high } \\
\text { concentrate }\end{array}$ \\
\hline Vaccination & $\begin{array}{l}\text { Treating animal from infectious diseases and producing safe } \\
\text { products }\end{array}$ \\
\hline Transhumance & $\begin{array}{l}\text { Unidirectional movement of the herd in searching of } \mathrm{H}_{2} \mathrm{O} \text { and } \\
\text { forage }\end{array}$ \\
\hline Emergency destocking & Reducing herd size as result of disease's outbreak \\
\hline $\begin{array}{l}\text { Water and soil conservation } \\
\text { activities }\end{array}$ & Aims at increasing food and forage production \\
\hline Changing herd composition & $\begin{array}{l}\text { Keeping only animals that have developed strong } \\
\text { resilience }\end{array}$ \\
\hline Income generating activities & Undertaking various activities capable of boosting revenue \\
\hline Forage cultivation & Selecting and growing forage to meet its increasing demand \\
\hline
\end{tabular}

question (4 climate change adaptation policies), then $J(J-1)$ best-worst pairs of best-worst choices are possible.

By following this approach, our data were analyzed using random utility framework which is well rooted in microeconomics (McFadden 1974), whereby a given respondent $\mathrm{n}$ derives from the selected best-worst pairs in each BWS question $t$ is the difference in utility between the $j$ best and $k$ worst policies.

This can be mathematically expressed:

$$
U_{n j t}=\mu_{j t}-\mu_{k t}+\varepsilon_{n j t}
$$

where $\mu$ is the vector of estimated importance parameters of the best and worst climate change policies ( $j$ and $k$ respectively) relative to some policy normalized to zero for identification.

The probability that respondents choose item $j$ as best and $k$ as worst out of $J$ items in BWS question $t$ is the probability that the difference in utility of the chosen items $\left(U_{n j t}\right.$ and $\left.U_{n k t}\right)$ is greater than all other $J(J-1)-1$ possible differences within each BWS question (Lusk and Briggeman 2009). While several econometric methods can be used to model this behavior, mixed logit is the most widely used estimation procedure, because it is flexible and can approximate any random utility model (Train 2009).

The mixed logit model and the probability that an individual $n$ chooses $j$ as best and $k$ as worst can be mathematically written as follows: 


$$
P_{n j}=\int \mu \prod_{t=1}^{T} \frac{e^{\left[\mu_{n j t}-\mu_{n k t}\right]}}{\sum_{l=1}^{J} \sum_{m=1}^{J} e^{\left[\mu_{n l t}-\mu_{n m t}\right]-J}} f\left(\mu_{n}\right) d \mu_{n}
$$

where $f\left(\mu_{n}\right)$ is the density of the importance parameters $\mu_{n}$.

The share of preferences for each climate change adaptation policy can be expressed as follows:

$$
\varphi_{j}=\frac{e^{\mu_{j}}}{\sum_{k=1}^{j} e^{\mu_{k}}}
$$

where $\varphi_{j}$ is the share of preference for a given climate change adaptation policy.

\section{Results}

Data were collected via well-structured questionnaire delivered to a sample of 271 respondents. Summary statistics and variable definitions are reported in Table 2. Most of the respondents have an average of 40 years and about $76 \%$ of respondents were male and $84 \%$ of the respondents were married. About $75 \%$ of respondents were uneducated, and about $52 \%$ and $27 \%$ of our sample have an annual income below 90,000 FCFA and between 90,0000 and 180,000 FCFA, respectively. In addition, average household size was 8 persons with an average of 16 and 24 respectively for large animal and small animal. About $87 \%$ of respondents strongly believe that climate change and environment are correlated.

Table 3 reports estimates from mixed logit models for both R and SAS software. Coefficients reflect the importance of each 12 climate change adaptation polices to forage cultivation, which was normalized to zero for identification purpose. Results show that based on $\mathrm{R}$ software estimation, strategic mobility followed by mutual assistance, settlement, strategic destocking, prolific animal selection, sheep and cattle fattening, vaccination, transhumance, emergency destocking, water and soil

Table 2 Characteristics of surveyed respondents

\begin{tabular}{l|l|l|l}
\hline Variable & Definition & Mean & Standard deviation (SD) \\
\hline Age & Age in number & 40 & 12 \\
\hline Genre & 1 if male, 0 female & 0.76 & 0.42 \\
\hline Marital status & 2 if married, 0 otherwise & 0.84 & 0.51 \\
\hline Education & 1 uneducated, 0 other & 0.25 & 0.22 \\
\hline Base: Income3 & Above 180,000 FCFA & $\mathbf{0 . 0 0}$ & $\mathbf{1}$ \\
\hline Income1 & Below 90,000 FCFA & 0.52 & 0.27 \\
\hline Income2 & $90,000-180,000$ FCFA & 0.27 & 0.52 \\
\hline Family size & Size in numbers & 8 & 5 \\
\hline Large animal size & Size in numbers & 16 & 18 \\
\hline Small animal size & Size in numbers & 24 & 25 \\
\hline Climate and environment & 1 if yes & 0.87 & 0.49 \\
\hline
\end{tabular}


Table 3 Mixed logit models for best-worst scaling data: software and coding method accuracies

\begin{tabular}{|c|c|c|c|}
\hline \multicolumn{2}{|l|}{ R software } & \multicolumn{2}{|l|}{ SAS software } \\
\hline $\begin{array}{l}\text { Agropastoralists' climate } \\
\text { change strategies }\end{array}$ & Estimate & $\begin{array}{l}\text { Agropastoralists' climate } \\
\text { change strategies }\end{array}$ & Estimate \\
\hline Strategic mobility & $0.887 *(0.088)$ & Settlement & $0.571 *(0.080)$ \\
\hline Mutual assistance & $0.587 *(0.089)$ & Emergency destocking & $0.369 *(0.075)$ \\
\hline Settlement & $0.582 *(0.076)$ & Prolific animal selection & $0.347 *(0.085)$ \\
\hline Strategic destocking & $0.528 *(0.077)$ & $\begin{array}{l}\text { Water and soil conservation } \\
\text { activities }\end{array}$ & $0.299 *(0.068)$ \\
\hline Prolific animal selection & $0.521 *(0.072)$ & Strategic mobility & $0.264 *(0.067)$ \\
\hline Sheep and cattle fattening & $0.515 *(0.079)$ & Transhumance & $0.214 *(0.069)$ \\
\hline Vaccination & $0.483 *(0.071)$ & Mutual assistance & $0.172 *(0.073)$ \\
\hline Transhumance & $0.407 *(0.075)$ & Sheep and cattle fattening & $0.080(0.074)$ \\
\hline Emergency destocking & $0.266 *(0.074)$ & Income generating income & $0.052(0.066)$ \\
\hline $\begin{array}{l}\text { Water and soil conservation } \\
\text { activities }\end{array}$ & $0.183 *(0.075)$ & Vaccination & $-0.059(0.066)$ \\
\hline Changing herd composition & $0.181 *(0.075)$ & Strategic destocking & $-0.142(0.066)$ \\
\hline Income generating activities & $0.048(0.079)$ & Changing herd composition & $-0.583(0.079)$ \\
\hline Base: Forage cultivation & 0.0000 & Baseline: Forage cultivation & 0.000 \\
\hline \multicolumn{2}{|c|}{ Standard deviation estimates } & \multicolumn{2}{|c|}{ Standard deviation estimates } \\
\hline Sd.(Strategic mobility) & $1.210 *(0.161)$ & Sd.(Settlement) & $1.068 *(0.153)$ \\
\hline Sd.(Mutual assistance) & $1.631 *(0.163)$ & Sd.(Emergency destocking) & $1.106 *(0.148)$ \\
\hline Sd.(Settlement) & $0.598 *(0.191)$ & $\begin{array}{l}\text { Sd.(Prolific animal } \\
\text { selection) }\end{array}$ & $1.430 *(0.152)$ \\
\hline Sd.(Strategic destocking) & $0.814 *(0.163)$ & $\begin{array}{l}\text { Sd.(Water and soil } \\
\text { conservation activities) }\end{array}$ & $0.330(0.251)$ \\
\hline $\begin{array}{l}\text { Sd.(Prolific animal } \\
\text { selection) }\end{array}$ & $0.104(0.522)$ & Sd.(Strategic mobility) & $0.513 *(0.201)$ \\
\hline $\begin{array}{l}\text { Sd.(Sheep and cattle } \\
\text { fattening) }\end{array}$ & $0.801 *(0.158)$ & Sd.(Transhumance) & $0.549 *(0.178)$ \\
\hline Sd.(Vaccination) & $0.129(0.397)$ & Sd.(Mutual assistance) & $0.935 *(0.151)$ \\
\hline Sd.(Transhumance) & $0.895 *(0.155)$ & $\begin{array}{l}\text { Sd.(Sheep and cattle } \\
\text { fattening) }\end{array}$ & $1.069 *(0.148)$ \\
\hline Sd.(Emergency destocking) & $0.897(0.153)$ & $\begin{array}{l}\text { Sd.(Income generating } \\
\text { activities) }\end{array}$ & $0.044(0.440))$ \\
\hline $\begin{array}{l}\text { Sd.(Water and soil } \\
\text { conservation activities) }\end{array}$ & $0.879 *(0.151)$ & Sd.(Vaccination) & $0.338(0.247)$ \\
\hline $\begin{array}{l}\text { Sd.(Changing herd } \\
\text { composition) }\end{array}$ & $0.912 *(0.150)$ & Sd.(Strategic destocking) & $0.223(0.374)$ \\
\hline $\begin{array}{l}\text { Sd.(Income generating } \\
\text { activities) }\end{array}$ & $1.210 *(0.151)$ & $\begin{array}{l}\text { Sd.(Changing herd } \\
\text { composition) }\end{array}$ & $0.974 *(0.149)$ \\
\hline Log likelihood & -8586.9 & -8845 & \\
\hline Numbers of observations(N) & 14,612 & 14,612 & \\
\hline Run time & $11 \mathrm{~m}: 22 \mathrm{~s}$ & $7 \mathrm{~m}: 43 \mathrm{~s}$ & \\
\hline
\end{tabular}

Numbers in parentheses are standard errors, * denotes mean importance of the policy which is statistically different from forage cultivation, Sd stands for standard deviations 
conservation activities, and changing herd composition are the most climate change adaptation policies with a significant difference to forage cultivation. Standard deviation estimates for 12 climate change adaptation policies obtained from $\mathrm{R}$ software were statistically and highly significant, implying that heterogeneity is a pattern when analyzing climate policies within the population. Table 2 also reports SAS software estimates. Results reveal that settlement followed by emergency destocking, prolific animal selection, water and soil conservation activities, strategic mobility, transhumance, and mutual assistance are the most important climate change adaptation polices relative to forage cultivation. Results also suggest that standard deviation estimates for settlement, emergency destocking, prolific animal selection, water and soil conservation activities, strategic mobility, transhumance, mutual assistance, sheep and cattle fattening, and changing herd composition are statistically significant, revealing that these estimates do vary in the population and thereby confirming heterogeneity pattern. Heterogeneity pattern when analyzing data in R is higher than heterogeneity pattern with SAS.

Table 3 also shows that R and SAS generated different mean estimates. For instance, the mean estimates for strategic mobility were 0.887 and 0.264 respectively for R and SAS. Similarly, the mean estimates for mutual assistance were 0.587 and 0.172 respectively for $\mathrm{R}$ and SAS. The mean estimates for settlement were 0.582 and 0.571 respectively for $\mathrm{R}$ and SAS. The mean estimates generated by $\mathrm{R}$ are all statistically significant. Similarly, the standard error estimates for strategic mobility, mutual assistance are higher for R than SAS, while standard error estimates for settlement and prolific animal selection are higher for SAS than R. This implies that estimates of standard errors considerably diverge across R and SAS. The standard deviation estimates are generally higher and significant for R than SAS; implying heterogeneity pattern is highly significant for R than SAS. Consequently, R software accurately predicted heterogeneity pattern than SAS.

Table 4 reports share of preferences for R and SAS software estimates. Results show that $12.17 \%, 9.02 \%$, and $8.97 \%$ of respondents viewed strategic mobility, mutual assistance, and settlement as the most desirable climate change adaptation policies, respectively. Based on SAS estimates, $11.63 \%, 9.51 \%$, and $9.30 \%$ of respondents viewed settlement, emergency destocking, and prolific animal selection as the most desirable climate change adaptation policies, respectively. This indicates that share of preference for settlement estimated with SAS is higher than estimate from R. Conversely, share of preference for strategic mobility estimated with R is higher than estimate from SAS. Share of preference for mutual assistance under R is higher than that of SAS. This shows that mixed results prevail while estimating share of preferences under R and SAS. Results also indicate that SAS's algorithm converges faster than that of $\mathrm{R}$.

Table 5 reports the intention to vote for or against each climate change adaptation policy. Results based on R estimation show that more than $70 \%$ of respondents would vote for the implementation of policies such as prolific animal selection $(100 \%)$, vaccination $(100 \%)$, settlement $(84 \%)$, strategic mobility $(77 \%)$, strategic destocking, and sheep and cattle fattening (74\%). Forage cultivation $(50 \%)$ and income generating activities (52\%) had the lowest vote share among respondents. 
Table 4 Share of preferences based on R and SAS estimates

\begin{tabular}{l|r|l|r}
\hline \multicolumn{2}{c}{$\mathrm{R}$} & \multicolumn{2}{c}{ SAS } \\
\hline Strategic mobility & $12.17 \%$ & Settlement & $11.63 \%$ \\
\hline Mutual assistance & $9.02 \%$ & Emergency destocking & $9.51 \%$ \\
\hline Settlement & $8.97 \%$ & Prolific animal selection & $9.30 \%$ \\
\hline Strategic destocking & $8.50 \%$ & $\begin{array}{l}\text { Water and soil conservation } \\
\text { activities }\end{array}$ & $8.86 \%$ \\
\hline Prolific animal selection & $8.44 \%$ & Strategic mobility & $8.56 \%$ \\
\hline Sheep and cattle fattening & $8.39 \%$ & Transhumance & $8.14 \%$ \\
\hline Vaccination & $8.13 \%$ & Mutual assistance & $7.81 \%$ \\
\hline Transhumance & $7.53 \%$ & Sheep and cattle fattening & $7.12 \%$ \\
\hline Emergency destocking & $6.54 \%$ & Income generating income & $6.92 \%$ \\
\hline $\begin{array}{l}\text { Water and soil conservation } \\
\text { activities }\end{array}$ & $6.02 \%$ & Vaccination & $6.20 \%$ \\
\hline Changing herd composition & $6.01 \%$ & Strategic destocking & $5.70 \%$ \\
\hline Income generating activities & $5.26 \%$ & Changing herd composition & $3.67 \%$ \\
\hline Base: Forage cultivation & $5.01 \%$ & Baseline: Forage cultivation & $6.57 \%$ \\
\hline
\end{tabular}

Results based on SAS estimates indicate that more than $70 \%$ of respondents would vote the implementation of policies such as income generating activities (88\%), water and soil conservation activities (82\%), and settlement and strategic mobility (70\%). Strategic destocking (26\%) and changing herd composition $(27 \%)$ had the lowest vote share among respondents. Results from Tables 3 and 4 further suggest that concordance between preferences for climate change adaptation polices and voting behavior does exist. Voting implementation results reveal that R and SAS estimates greatly vary.

\section{Conclusion}

A mosaic of climate change adaptation policies have been proposed to build rural household resilience capacity and diversify income and food strategies and improve their livelihood.

This chapter uses BWS approach to elicit Niger agropastoralists preferences for climate change adaptation policies. Using data collected from 271 agropastoralists, results indicate that agropastoralists have a clear preference for settlement, emergency destocking, prolific animal selection, water and soil conservation activities, strategic mobility, transhumance, and mutual assistance. While results also suggest that mean, standard error and standard deviation estimates of these preferences vary across R and SAS package, R package yielded more accurate results than SAS.

Results further suggest that share of preferences and vote for climate change adaptation policy implementation are software package dependent. Future research is to study the stability of climate change adaptation policies overtime. Lusk (2012) stated that public policy is highly interventionist and that policy preferences are more 


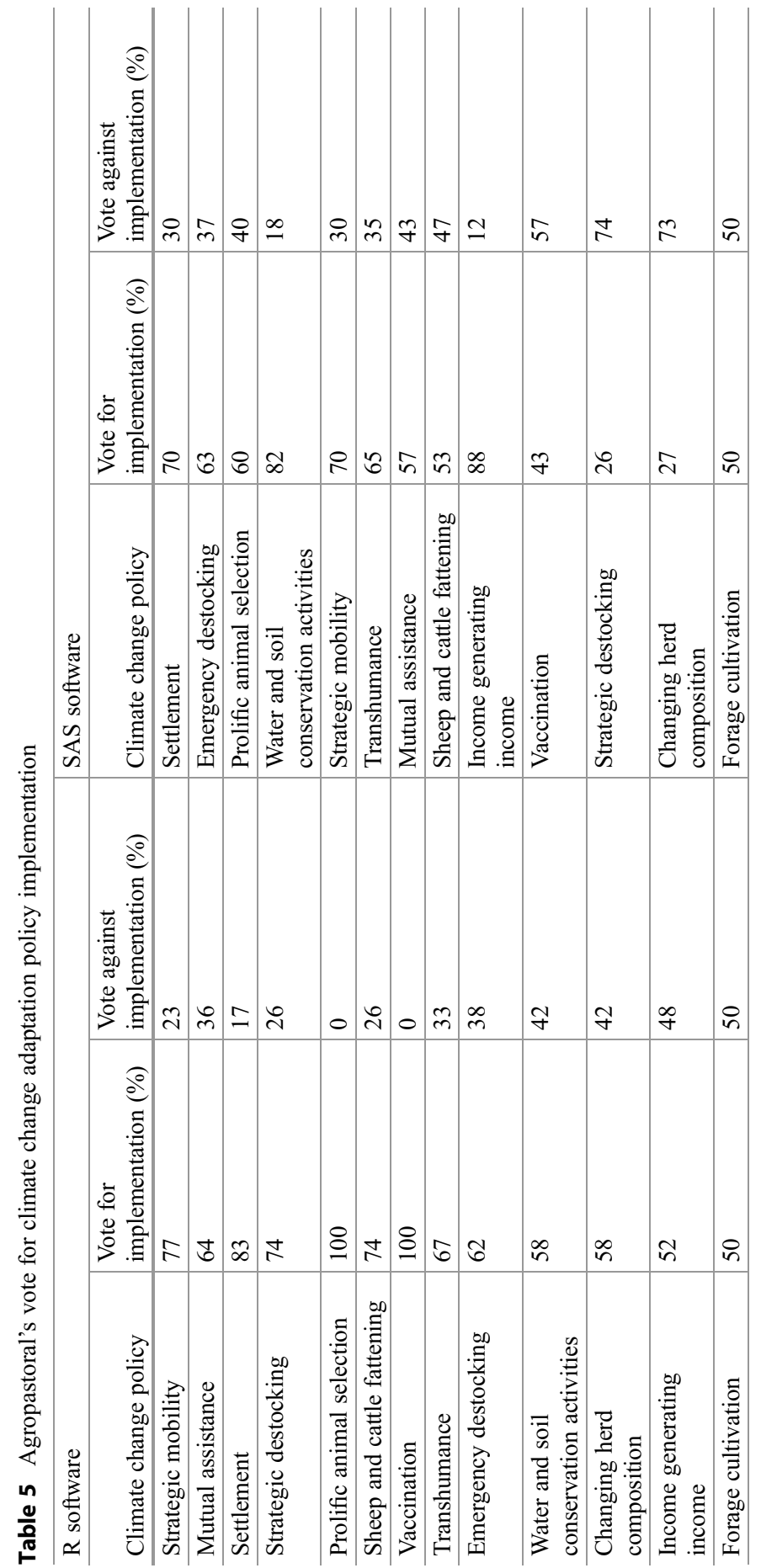


likely to change external shocks when climate change hit, food safety crisis occurred, and negative externalities happened.

\section{References}

Chang JB, Lusk JL (2011) Mixed logit models: accuracy and software choice. J Appl Econ 26:167_ 172

Flynn T, Marley T (2014) Best-worst scaling: theory and methods. In: S. Hess and A. Daly (eds), Handbook of Choice Modelling. Cheltenham, UK: Edward Elgar 178-201

Louviere JJ, Flynn TN, Marley AAJ (2015) Best-worst scaling: theory, methods and applications. Cambridge University Press, Cambridge

Lusk JL (2012) The political ideology of food. Food Policy 37(5):530-542

Lusk JL, Briggeman BC (2009) Food Values. Am J Agric Econ 91(1):184-196

Lusk JL, McCluskey J (2018) Understanding the impacts of food consumer choice and food policy outcomes. Appl Econ Perspect Policy 40(1):5-21

Marley AA, Louvriere JJ (2005) Some probabilistic models of best, worst, and best-worst choices. J Math Psychol 49(6):464-480

McFadden D (1974) Conditional logit analysis of qualitative choice behavior. Frontiers in Econometrics. New York: Zarembka

McFadden D, Train K (2000) Mixed MNL models for discrete response. J Appl Econ 15(5):447470. https://doi.org/10.1002/1099-1255(200009/10)15:5447::AID-JAE5703.0.CO;2-1

Tabbo AM, Amadou Z, Danbaky AB (2016) Evaluating farmers' adaptation strategies to climate change: a case study of Kaou local government area, Tahoua State, Niger Republic. Jàmbá: J Disaster Risk Stud 8(3):a241. https://doi.org/10.4102/jamba.v8i3.241

Train K (2009) Discrete choice methods with simulation. Cambridge University Press, Cambridge, UK

Open Access This chapter is licensed under the terms of the Creative Commons Attribution 4.0 International License (http://creativecommons.org/licenses/by/4.0/), which permits use, sharing, adaptation, distribution and reproduction in any medium or format, as long as you give appropriate credit to the original author(s) and the source, provide a link to the Creative Commons license and indicate if changes were made.

The images or other third party material in this chapter are included in the chapter's Creative Commons license, unless indicated otherwise in a credit line to the material. If material is not included in the chapter's Creative Commons license and your intended use is not permitted by statutory regulation or exceeds the permitted use, you will need to obtain permission directly from the copyright holder. 